\title{
Un varón con una lesión verrucosa en el pie... (carcinoma verrucoso, epitelioma cuniculatum)
}

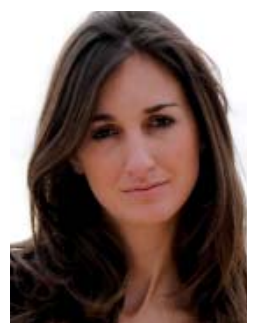

Virginia Sanz Motilva Residente de $2^{\circ}$ año de Dermatología. Hospital Universitario 12 de Octubre. Madrid.

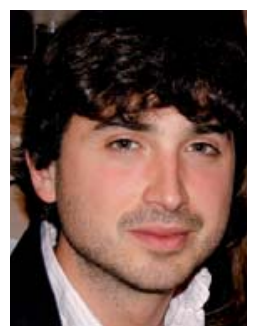

Antonio Martorell Calatayud

Jefe de la Sección de Dermatología. Hospital General de Requena (Valencia).
Mi paciente es un varón de 55 años que acudió a la consulta de Dermatología por una lesión ligeramente dolorosa de 13 meses de evolución, de crecimiento lento y progresivo, localizada en la región volar del pie derecho (fig. 1). El paciente, dedicado al trabajo agrícola, no presentaba antecedentes de interés ni refería historia de traumatismo previo en dicho área.

La exploración física reveló la existencia de una masa verrucosa hiperqueratósica de superficie cerebriforme, de consistencia dura a la palpación, que de forma característica mostraba amplios senos cargados de queratina. La tumoración medía $3,5 \mathrm{~cm}$ de diámetro mayor y se localizaba en la región correspondiente a la base del prime-

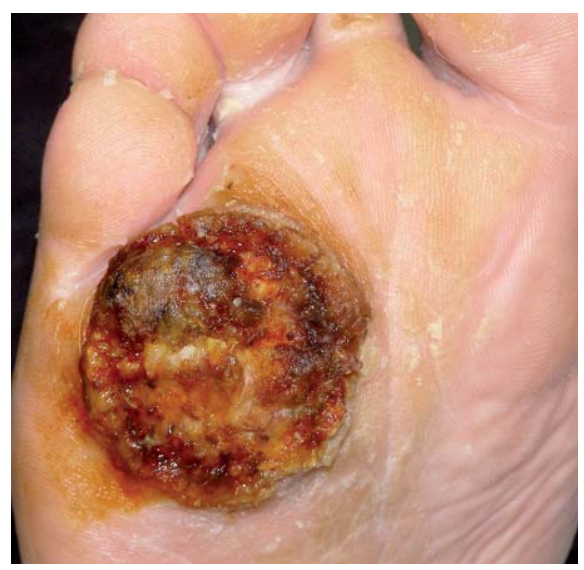

Figura 1. Placa redondeada excrecente con superficie queratósica y bien delimitada, localizada en la planta del pie derecho. ro y segundo metatarsiano del pie derecho.

El estudio histológico mostró la existencia de una proliferación tumoral con un doble componente endoexofitico (fig. 2). El componente exofítico consistía en una acantosis epidérmica con hiperqueratosis y en ocasiones paraqueratosis en la región papilar. El componente endofítico estaba compuesto por un epitelio escamoso bien diferenciado que mostraba un crecimiento hacia la dermis, formando procesos a modo de bulbo que empujaban las estructuras adyacentes sin mostrar un carácter infiltrativo (fig. 3). El pleomorfismo celular era mínimo, el número de mitosis era escaso y estaban localizadas en la membrana basal.

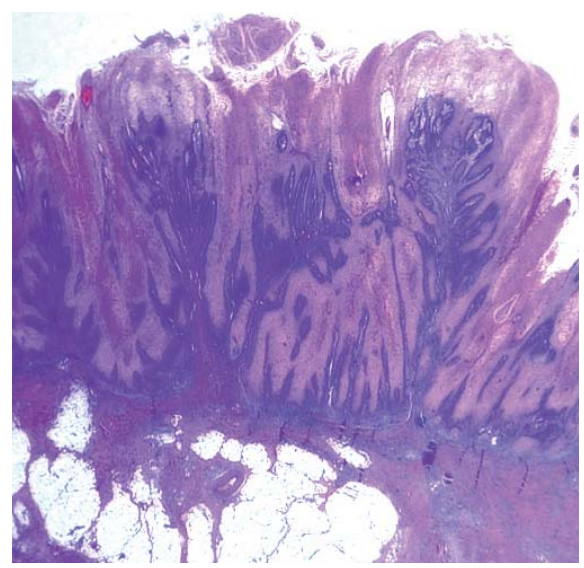

Figura 2. Imagen panorámica de la lesión. Proliferación epidérmica endoexofítica que invade de forma masiva la dermis (H-E, x10). 


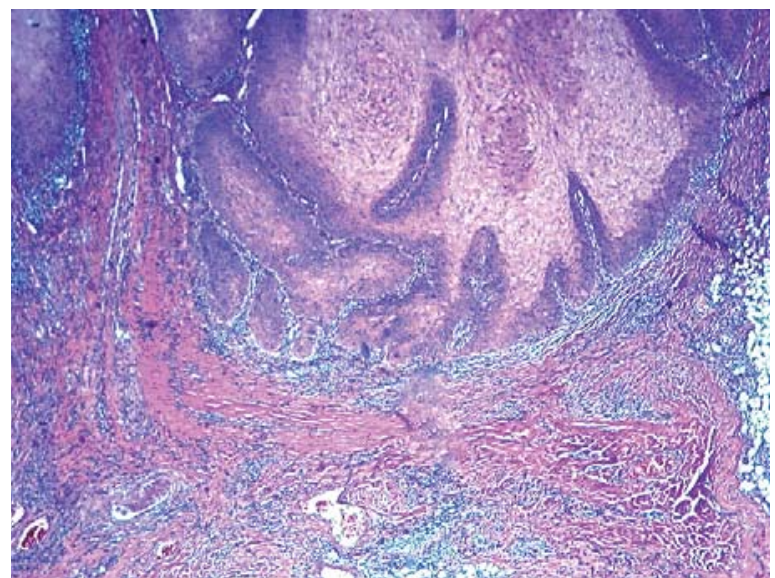

Figura 3. Invasión expansiva de la tumoración epidérmica, formada por queratinocitos bien diferenciados con escaso número de mitosis $(\mathrm{H}-\mathrm{E}, \mathrm{x} 100)$.

El estudio mediante hibridación in situ de parte de la pieza de biopsia mostró positividad para VPH 18

Las características clínicas e histológicas de este paciente son compatibles con el diagnóstico de carcinoma verrucoso, que en la planta del pie se conoce como epitelioma cuniculatum.

La resonancia magnética nuclear practicada previamente al acto quirúrgico mostró una masa sólida bien limitada al tegumento, con respeto a la estructura ósea subyacente.

El tratamiento consistió en la extirpación de la lesión mediante cirugía micrográfica de Mohs en diferido; fueron necesarios dos estadios quirúrgicos para alcanzar márgenes libres de enfermedad. Tras 5 años de seguimiento, el paciente no ha mostrado recidiva del proceso tumoral maligno.

\section{DISCUSIÓN}

El carcinoma verrucoso es un tipo bien diferenciado e infrecuente de carcinoma epidermoide de bajo grado de piel y mucosas. El término clinicopatológico, acuñado por Ackerman en 19481, define una tumoración con un comportamiento clínico local agresivo, aunque con escasa capacidad de diseminación a distancia. Suele localizarse con mayor frecuencia en la planta del pie y afecta prin- cipalmente a varones de edades comprendidas entre los 52 y los 65 años ${ }^{2}$.

El carcinoma verrucoso recibe clásicamente varias denominaciones según su localización anatómica. Cuando se encuentra en la región anogenital, se denomina tumor de Buschke-Löwenstein, mientras que en la mucosa oral recibe el nombre de papilomatosis oral florida o tumor de Ackerman. El carcinoma verrucoso en la planta del pie se conoce como epitelioma o carcinoma cuniculado. Esta última forma se parece clínicamente a una gran verruga vulgar de crecimiento endoexofítico, que presenta múltiples orificios en su superficie a modo de túneles, que le confieren un aspecto similar a una madriguera de conejo, lo que justifica la denominación de «cuniculado». Por último, se utiliza el término simple de carcinoma verrucoso cutáneo cuando se localiza en otras zonas de la superficie corporal ${ }^{3}$.

La etiopatogenia del carcinoma verrucoso no ha sido aún aclarada por completo, pero se reconocen varios factores que pueden estar implicados e incluyen: traumatismos, carcinógenos químicos, inflamación crónica, radiación previa, inmunodepresión e infección por el virus del papiloma humano. Entre los serotipos hallados destacan el 16 y el 18, pues son los subtipos de alto riesgo, dado su mayor poder oncogénico ${ }^{4}$.

Histológicamente, el carcinoma verrucoso se identifica como una neoplasia de carácter expansivo compuesta por queratinocitos maduros, bien diferenciados y sin atipia significativa. Las mitosis suelen ser escasas o inexistentes. La presencia de senos centrales de queratina y microabcesos epidérmicos se correlaciona con su aspecto macroscópico, caracterizado por su superficie recorrida por surcos y depresiones. El tumor presenta un margen profundo que avanza de forma característica en un frente amplio, formando prolongaciones bulbosas con poca evidencia de infiltración. En pocos casos, puede presentar invasión perineural o vascular ${ }^{5}$.

Se considera un tumor de bajo grado, pues el desarrollo de metástasis a distancia es excepcional. 
Sin embargo, localmente es muy agresivo, con riesgo de destrucción de estructuras cercanas, incluido el hueso subyacente ${ }^{6}$.

El tratamiento de elección es la extirpación quirúrgica por técnica micrográfica de Mohs, para garantizar la presencia de márgenes libres, con preservación anatómica y funcional de las estructuras adyacentes. En caso de infiltración profunda, puede ser necesaria una técnica quirúrgica más agresiva, con amputación parcial o completa en el caso del pie. Otras modalidades de tratamiento incluyen inmunoterapia, laserterapia, criocirugía, tratamiento con retinoides (acitretino), terapia fotodinámica y quimioterapia. El tratamiento con radioterapia no es recomendable, pues existe el riesgo de transformación en variantes más agresivas de peor pronóstico (carcinoma espinocelular anaplásico) $)^{6,7,8,9}$.

El caso de nuestro paciente evoluciona favorablemente, de acuerdo a las características habituales en este tipo de tumor y localización.

\section{BIBLIOGRAFÍA}

1. Ackerman LV. Verrucous carcinoma of the oral cavity. Surgery. 1948;23:670.

2. Schwartz RA. Verrucous carcinoma of the skin and mucosa. J Am Acad Dermatol. 1995;32:1-21.

3. Assaf C, Steinhoff M, Petrov, Geilen CC, de Villiers EM, SchutzEhrenburg $\mathrm{U}$, et al. Verrucous carcinoma of the axilla: case report and review. J Cutan Pathol. 2004;31:199-204.

4. Floristán MU, Feltes RA, Sáenz JC, Herranz P. Carcinoma verrugoso del pie asociado a virus papiloma humano tipo 18. Actas Dermosifiliogr. 2009;100:433-4.

5. Petter G, Haustein UF. Histologic subtyping and malignancy assesment of cutaneous squamus cell carcinoma. Dermatol Surg. 2000;25:521-30.

6. Pattee SF, Bordeaux J, Mahalingam M, Nitzan YB, Maloney ME. Verrucous carcinoma of the scalp. J Am Acad Dermatol. 2007; 56:506-7.

7. Nikkels AF, Thition L, Quatresooz P, Piérard GE. Photodynamic theraphy for cutaneous verrucous carcinoma. J Am Acad Dermatol. 2007;57:516-9.

8. Kuan YZ, HSU HC, Kuo TT, Huang YH, Ho HC. Multiple verrucous carcinomas treated with acicretin. J Acad Dermatol. 2007;56(2 Suppl):S29-32.

9. Miller SJ. The National Comprehensive Cancer Network guidelines of care for nonmelanoma skin cancers. Dermatol Surg. 2000;26:289-92. 